\title{
CYP2C19 genotype does not represent a genetic predisposition in idiopathic systemic lupus erythematosus
}

Selim Kortunay, Atila Bozkurt, Lise Bathum, Nursabah E Basci, Meral Çalgüneri, Kim Brøsen, S Oḡuz Kayaalp

\begin{abstract}
Background-The aetiology of systemic lupus erythematosus (SLE) is still unknown. In several cases, however, chemicals or drugs were identified as aetiological agents and associations with certain phenotypes of drug metabolising enzymes have been reported. The purpose of this study was to discover if there is an association between CYP2C19 polymorphism and susceptibility to SLE.

Methods-Racemic mephenytoin $(100 \mathrm{mg}$ orally) was given to healthy volunteers $(n=161)$ and SLE patients $(n=37)$ and then S-mephenytoin and $\mathbf{R}$-mephenytoin were determined in eight hour urine samples. A $10 \mathrm{ml}$ blood sample was obtained from healthy volunteers $(n=80)$ and SLE patients $(n=69)$ for genotypic assay. Each blood sample was tested for the detection of $C Y P 2 C 19{ }^{\star} 1$ and $C Y P 2 C 19{ }^{\star} 2$ (formerly wt and $\mathrm{m} 1$ respectively) by oligonucleotide ligation assay.

Results-The ratio of S/R-mephenytoin ranged from $<0.1$ to 1.293 in healthy subjects and from $<0.1$ to 1.067 in SLE patients. PM phenotype was observed in 2 of 37 patients with idiopathic SLE (5.4\%) and 6 of 161 healthy subjects $(3.7 \%)$. There were no significant differences in the frequency of PM phenotypes between the groups (Fisher's exact test, $p=0.64$ ) or in the frequency distribution profiles of ratios of S-mephenytoin to R-mephenytoin. No significant differences in distribution of overall genotypes and in allele frequencies were observed between the two groups. No significant relation was found between clinical features and the overall genotype. Conclusion-The results of this study indicate that $C Y P 2 C 19$ genotype does not represent a genetic predisposition in idiopathic SLE patients.

(Ann Rheum Dis 1999;58:182-185)
\end{abstract}

University, Ankara,

Turkey

M Çalgüneri

Department of Clinical Pharmacology,

Institute of Medical

Biology, Odense

University, Odense,

Denmark

K Brøsen

Correspondence to:

Dr S Kortunay.

Accepted for publication

25 November 1998
The aetiology of the systemic lupus erythematosus (SLE), a multisystem connective tissue disease, is unknown. In several cases, however, for example, drug induced lupus erythematosus, drugs were identified as aetiological agents $^{1}$ and associations with certain phenotypes of drug metabolising enzymes have been reported. ${ }^{2}$

One of the well described and genetically the cytochromes P450 is the CYP2C19 metadetermined polymorphic drug metabolisms by bolic polymorphism. The CYP2C19 poor metaboliser phenotype is present in approximately $3 \%$ of white populations ${ }^{3}$ and up to $18 \%$ of the Asian populations. ${ }^{4}$ This enzyme is clinically important because it is involved in the metabolism of a number of drugs, such as mephenytoin, ${ }^{5}$ diazepam, ${ }^{6}$ proguanil, ${ }^{7}$ and omeprazole. ${ }^{8}{ }^{9}$ Recently several mutations have been found in the CYP2C19 gene. The principal genetic defect is a single base mutation in exon 5 of the $C Y P 2 C 19\left(C Y P 2 C 1{ }^{\star}{ }^{\star} 2\right)$ gene (m1), which accounts for approximately 75$83 \%$ of the poor metaboliser alleles in both Japanese and white subjects. ${ }^{10}$ Two other mutated alleles have been identified - a single base mutation (G-A) in exon 4 of the CYP2C19 (CYP2C19*3), which accounts for the remaining poor metabolisers of CYP2C19 in Japanese ${ }^{11}$ and a very rare mutation $\left(\mathrm{C}_{1297}-\mathrm{T}\right)$ until now only seen in one subject. ${ }^{12}$ The $\left(C Y P 2 C 19{ }^{\star} 3\right) \mathrm{m} 2$ mutation is found in white populations albeit with a much lower frequency. ${ }^{13}$

Genetic polymorphisms of drug metabolising enzymes have an important role in determining susceptibility to rheumatic diseases and adverse drug reactions. For example, CYP2D6 polymorphism has been linked with susceptibility to various diseases including SLE $^{14}$ and ankylosing spondylitis, ${ }^{15}$ but not scleroderma ${ }^{16}$ and rheumatoid arthritis. ${ }^{17}$ On the other hand, SLE patients differ from normal subjects in their patterns of oxidative metabolism of certain drugs and chemicals. ${ }^{18-21}$ Thereby differences in patterns of oxidative metabolism may be potentially important in the pathogenesis of SLE with activating drugs or environmental chemicals to toxic metabolites. Recently, May et al reported that CYP2C19 activity is reduced in scleroderma. ${ }^{16}$

Our objective was to get an insight into whether patients with SLE show impaired CYP2C19 activity. Also we ascertained whether there was an association between particular CYP2C19 genotypes and susceptibility to SLE, and whether CYP2C19 polymorphism is linked to any specific clinical features of SLE.

\section{Methods}

The study was approved by the ethics committees of Hacettepe University Medical School and the Ministry of Health of Turkey. Seventy patients with SLE according to the American Rheumatism Association criteria $^{22}$ were recruited from rheumatology outpatients department at the Hacettepe University Hospital. All 
Table 1 Comparison of genotypes in SLE patients and in controls

\begin{tabular}{lll}
\hline Genotype & Patients $(n=69)$ & Controls $(n=80)$ \\
\hline PM & $3(4.3 \%)(1.2,17.6)$ & $1(1.2 \%)(0.2,10.9)$ \\
Heterozygous EM & $11(15.7 \%)(7.2,33.1)$ & $17(21.2 \%)(10.9,38.1)$ \\
Homozygous EM & $55(80.0 \%)(56.1,91.9)$ & $62(77.6 \%)(56.3,89.8)$ \\
\hline
\end{tabular}

$95 \% \mathrm{CI}$ are shown.

Table 2 Allele frequencies in SLE patients and in controls

\begin{tabular}{lll}
\hline Allele & Patients $(n=138)$ & Controls $(n=160)$ \\
\hline CYP2C19^1 & $121(87.7 \%)(73.8,94.7)$ & $141(88.2 \%)(74.9,93.9)$ \\
CYP2C19*2 & $17(12.3 \%)(6.4,23.2)$ & $19(11.8 \%)(6.43,21.6)$ \\
\hline
\end{tabular}

$95 \%$ CI are shown.

patients and control subjects gave written informed consent to participate in the study. Six of the patients were male and 64 female, mean age 38.71 (SD 10.77) years. Before the diagnosis of SLE, none of these patients had received procainamide, hydralazine, isoniazid, anticonvulsants, or other drugs known to cause the lupus syndrome. All patients were maintained with their usual medications during the study. None of the patients was taking a medication known to be metabolised by the CYP2C19 or to inhibit it, or both. One hundred and sixty one unrelated healthy subjects, 121 male and 40 female, with average age 23 (SD 2) years, served as a control population. All were students or staff members of Hacettepe University, who were born in Turkey with Turkish parents. None of the subjects were regular alcohol users and had no history of liver or kidney disease.

PHENOTYPING

After emptying the bladder, 161 healthy volunteers and 37 idiopathic SLE patients took $100 \mathrm{mg}$ racemic mephenytoin tablet orally and then urine was collected over the subsequent eight hours. A $10 \mathrm{ml}$ aliquot was kept frozen at $-20^{\circ} \mathrm{C}$. No other drugs was taken by healthy volunteers for at least one week before the study.

S- and R-mephenytoin were measured by gas chromatography. ${ }^{23}$ Enantiomeric separation of mephenytoin was obtained using a chiral capillary column (Chirasil- Val III FSOT, $25 \mathrm{~m} \times 0.25 \mathrm{~mm}$, internal diameter, All-tech Associations) followed by nitrogen specific detection. The flow rates of helium, air, and hydrogen were adjusted to $2.0-2.5 \mathrm{ml} / \mathrm{min}, 100$ $\mathrm{ml} / \mathrm{min}$, and $3.0 \mathrm{ml} / \mathrm{min}$, respectively. Split and septum flow were adjusted to $45-50 \mathrm{ml} / \mathrm{min}$ and $2 \mathrm{ml} / \mathrm{min}$ respectively. The temperature of column, injector, and detector were adjusted to 180,250 , and $290^{\circ} \mathrm{C}$. In these chromotographic conditions, the retention times for the $\mathrm{S}$ - mephenytoin and for R-mephenytoin were 9.94 and 10.19 minutes, respectively. S- and $\mathrm{R}$-mephenytoin were extracted from urine samples by using chloroform. The reproducibility was less than $8 \%$ (coefficient of variation). The peak areas of S- and R- mephenytoin were used to calculate the $S / R$ mephenytoin ratio. In the urine samples in which R-mephenytoin but not S-mephenytoin was detected, the $S / R$ mephenytoin ratio was given the value of 0.1 based on the lower level of detection of the S-enantiomer. Subjects with $\mathrm{S} / \mathrm{R}$ mephenytoin ratio above 0.9 were phenotyped as poor metabolisers of mephenytoin. ${ }^{23}$

\section{GENOTYPING}

A $10 \mathrm{ml}$ blood sample was obtained from 80 healthy volunteers and 69 patients for genotypic assay and blood samples were kept frozen at $-20^{\circ} \mathrm{C}$.

CYP2C19 genotypes were determined by assay of leucocyte DNA extracted from blood samples. Each DNA sample was tested for the detection of $C Y P 2 C 19^{\star} 1, C Y P 2 C 19{ }^{\star} 2$ (formerly wt, $\mathrm{m} 1$, respectively) by oligonucleotide ligation assay as described recently. ${ }^{24}$

Analysis of mephenytoin and determination of CYP2C19 genotypes were performed at the Department of Clinical Biochemistry, Odense University Hospital, Denmark. Urine and blood samples were transported over dry ice and remained frozen on arrival in Odense.

\section{STATISTICAL METHODS}

Statistical analysis included $95 \%$ confidence interval (CI) of proportions, Fisher's exact test for comparison of genetic and phenotypic differences between populations and Student's $t$ test for comparison of age at onset of the disease. The level of statistical significance was set at $\mathrm{p}=0.05$ with two sided analysis.

\section{Results}

We initially determined whether there was an association between susceptibility to SLE and particular CYP2C19 genotypes. Subjects were assigned to three different classes of overall genotypes (poor metaboliser (PM), heterozygous extensive metaboliser (EM), and homozygous EM) on the basis of genotypic results. The frequencies of the three possible genotypes in the population with SLE and the control are shown in table 1 and the frequency of the wild-type and 2 mutant CYP2C19 alleles in table 2. There was no significant difference in the frequency of the three genotypes between controls and patients with SLE. Furthermore the frequency of the $C Y P 2 C 19^{\star} 1$ and $C Y P 2 C 19^{\star} 2$, alleles did not seem to differ between patients and controls.

The ratio of S-mephenytoin to $\mathrm{R}$-mephenytoin ranged from $<0.1$ to 1.293 in healthy subjects and from $<0.1$ to 1.067 in SLE patients. We observed PM phenotype in 2 of 37 patients with idiopathic SLE $(5.4 \%)$ and 6 of 161 healthy subjects $(3.7 \%)$. There were no significant differences in frequency of PM phenotypes between the groups (Fisher's exact test (two tailed) $\mathrm{p}=0.64$ ) or in the frequency distribution profiles of ratios of S-mephenytoin to R-mephenytoin.

Figure 1 (A) and (B) summarise the relation between the various genotypes and S/Rmephenytoin ratio for the patient group and control group. The median S/R-mephenytoin ratios for homozygous EM were similiar in patients with SLE and controls, 0.14 (range $<0.1-0.59$ ) and 0.20 (range $<0.1-0.8$ ), respectively. The median S/R-mephenytoin ratios in heterozygous EM patients with SLE and heterozygous EM controls were 0.21 (range 

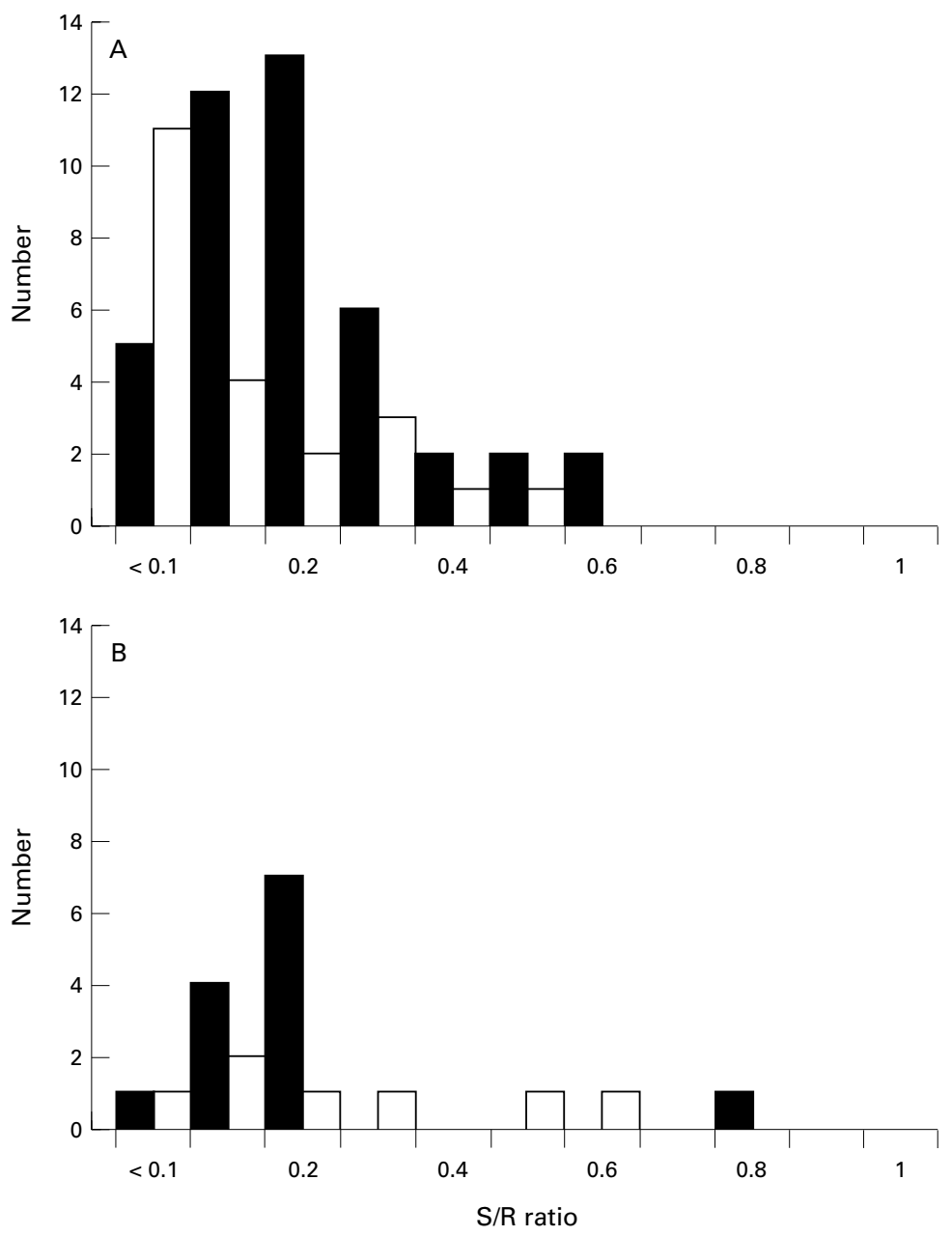

Figure $1 S / R$ mephenytoin ratios in $(A)$ homozygous EM and (B) heterozygous EM subjects. (Closed bars represent healthy controls, open bars SLE patients).

$0.02-0.68$ ) and 0.24 (range $0.08-0.87$ ), respectively. One genotypic PM in the control group and two genotypic PM in the SLE group showed urinary $\mathrm{S} / \mathrm{R}$ ratios $>0.9$ as expected. But unexpectedly one of the genotypic PM patients had lower urinary $S / R$ ratios.

There were five drugs being used by 21 or more patients at the time of the study. These included aspirin (38 patients), prednisone (32 patients), hydroxychloroquine (31 patients), cyclophosphamide (23 patients), and famotidine ( 21 patients). These patients showed urinary $S / R$ ratios no higher than expected. None of the patients was taking CYP2C19 substrates and/or inhibitors alone, or in combination.

Ten of the SLE patients gave a history of discoid lupus $(6.0 \%), 10$ arthritis $(6.0 \%), 3$ hypocomplementaemia $(5.0 \%), 2$ pleurisy $(3.3 \%), 2$ seizures $(3.3 \%), 2$ pericarditis $(3.3 \%), 2$ psychosis $(3.3 \%), 2$ glomerulonephritis $(3.3 \%)$. At the time of the study none $(0 \%)$ of the patients had a serum creatinine concentration higher than $1.5 \mathrm{mg} / \mathrm{dl}$ and 16 were positive for anti-DNA antibodies $(26.6 \%)$. There was no relation between genotype and titre of anti-nuclear antibodies, or any other clinical features of SLE at the start of study, or age of onset of the disease (data not shown).

\section{Discussion}

The cause of the SLE is unknown but in several cases, for example, drug induced lupus erythematosus, drugs were identified as aetiological agents ${ }^{1}$ and associations with certain phenotypes of drug metabolising enzymes have been reported. ${ }^{2}$ Evidence obtained in this study suggests that CYP2C19 genetic polymorphism was not associated with the occurrence of SLE. The phenotyping status in the control group was similar to those reported in the previous studies in the Turkish population ${ }^{25-27}$ suggesting that the control group used was representative. However, as the number of patients studied was small and the frequency of the poor metaboliser genotype in the control population is only $1.2 \%$, the statistical power of the study is limited. Although the SLE group consists mostly of women and the control group are mostly men, previous studies showed that sex and age did not significantly affect the polymorphic oxidation of mephenytoin. ${ }^{28}$

Inflammatory rheumatic diseases could affect the activity of many drug metabolising enzymes. Differences in patterns of oxidative metabolism involved in conversion of xenobiotics to toxic metabolites may potentially be important in the pathogenesis of rheumatic diseases. Oxidative metabolisms of certain drugs and chemicals were impaired in SLE patients. ${ }^{18-21}$ However, our study has clearly demonstrated that the majority of patients with SLE have normal levels of CYP2C19 activity.

Recently, May et al reported that CYP2C19 activity is reduced in scleroderma according to phenotyping data. ${ }^{16}$ More recently Flockhart et al also reported that CYP2C19 activity is reduced in eosinophilia-myalgia syndrome, another connective tissue disease, according to phenotyping data. ${ }^{29}$ However, only genotyping can establish whether such differences result from the disease or are because of an association between level of enzyme activity and disease susceptibility. As the genotypic data are not influenced by medications, diet, environment, or timing of urine collection, the determination of PM genotype is therefore straightforward.

In conclusion, our study has clearly demonstrated that the activity of the cytochrome P450 enzyme CYP2C19 is not impaired significantly in SLE patients nor does genetic variability at the CYP2C19 locus predispose to SLE. However, similar investigations of the other drug metabolising enzymes with differing substrate specificities and regulatory mechanisms need to be carried out.

Funding: this work was supported by grants from the Scientific and Technical Research Council of Turkey (COST B-SBAG1477). It contributes to the goals of COST Action $B_{1}$.

1 Young RL, Johnson KJ, Richardson BC. Biology of disease: new concepts in the pathogenesis of drug-induced lupus. Lab Invest 1995;73:746-59.

2 Uetrecht JP, Woosley RL. Acetylator phenotype and lupus erythematosus. Clin Pharmacokinet 1981;6:118-34.

3 Alvan G, Bechtel P, Iselius L, Gundert-Remy U. Hydroxylation polymorphism of debrisoquine and mephenytoin in tion polymorphism of debrisoquine and mephenytoin in
European populations. Eur J Clin Pharmacol 1990;39:

4 Brosen K, Skjelbo E, Flacks H. Proguanil metabolism is determined by the mephenytoin oxidation polymorphism in Vietnamese living in Denmark. Br J Clin Pharmacol 1995;36:105-8. 
5 Küpfer A, Preisig R. Pharmacogenetics of mephenytoin, a new drug hydroxylation polymorphism in man. Eur J Pharnew drug hydroxylation
macol 1984;26:753-9.

6 Bertilsson L, Kalow W. Why are diazepam metabolism and polymorphic S-mephenytoin hydroxylation associated with each other in white and Korean populations but not in Chinese populations? Clin Pharmacol Ther 1993;53:60810.

7 Ward SA, Helsby NA, Skjelbo E, Brosen K, Gram LF, Breckenridge AM. The activation of the biguanid antimalaria proguanil co-segregates with the mephenytoin oxidation polymorphism- a panel study. Br J Clin Pharmacol 1991;31:689-92.

8 Balain JD, Sukhova N, Harris JW, Hewett J, Pickle L, Goldstein JA, et al. The hydroxylation of omeprazole correlates with S-mephenytoin metabolism: A population study. Clin Pharmacol Ther 1995;57:662-9.

9 Chang M, Dahl M, Tybring G, Götharson E, Bertilsson L. Use of omeprazole as a probe drug for CYP2C19 S-mephenytoin hydroxylation phenotype and CYP2C19 S-mephenytoin hydroxylation phenotype an

10 deMorais SMF, Wilkinson GR, Blaisdell J, Nakamura K Meyer UR, Goldstein JA. The major genetic defect responsible for the polymorphism of S-mephenytoin metabolism in humans. J Biol Chem 1994;22:15419-22.

11 deMorais SMF, Grant RW, Blaisdell J, Meyer UA, Nakamura K, Goldstein J. Identification of a new genetic defect for the polymorphism of (S)-mephenytoin metabolism in Japanese. Mol Pharmacol 1994;46:594-8.

12 Xiao Z, Goldstein JA, Xie H, Blaisdell J, Wang W, Jiang C, al. Differences in the incidence of the CYP2C19 polymorphism affecting the S-mephenytoin phenotype in Chinese Han and Bai populations and identification of a new rare CYP2C19 mutant allele. J Pharmacol Exp Ther 1997;281: 604-9.

13 Brøsen K, deMorais SMF, Meyer UA, Goldstein JA. A multifamily study on the relationship between CYP2C19 tifamily study on the relationship between CYP2C19 genotype and S-mephenytoin

14 Baer AN, McAllister CB, Wilkinson GR, Woosley RL, Pincus $\mathrm{T}$. Altered distribution of debrisoquine oxidation phenotypes in patients with systemic lupus erythematosus.

15 Beyeler C, Armstrong M, Bird HA, Idle JR, Daly AK. Relationship between genotype for the cytochrome P450 CYP2D6 and susceptibility to ankylosing spondylitis and rheumatoid arthritis. Ann Rheum Dis 1996;55:66-8.

16 May DG, Black CM, Olsen NJ, Csuka ME, Tanner SB, Bellino $\mathrm{L}$, et al. Scleroderma is associated with differences in individual routes of drug metabolism: A study with dapsone, debrisoquine, and mephenytoin. Clin Pharmacol Ther 1990;48:286-95.
17 Beyeler C, Daly AK, Armstrong M, Astbury C, Bird HA, Idle JR. Phenotype/genotype relationships for the cytochrome P450 CYP2D6 in rheumatoid arthritis: influence of drug therapy and disease activity. J Rheumatol 1994;21: 1034-9.

18 Lahita RG, Bradlow HL, Kunkel HG, Fishman J. Alterations of estrogen metabolism in systemic lupus erythematosus. Arthritis Rheum 1979;22:1195-8.

19 Lahita R G, Bradlow H L, Fishman J. Increased 16- $\alpha$ hydroxylation of estradiol in systemic lupus erythematosus. J Clin Endocrinol Metab 1981;53:174-8.

20 Lahita RG, Kunkel HG, Bradlow HL. Increased oxidation of testosterone in systemic lupus erythematosus. Arthritis Rheum 1983;26:1517-21.

21 Drayer DE, Lorenzo B, Lahita RG, Robbins WC, Reidenberg MM. Microsomal hydroxylation as measured by pentobarbital elimination in patients with idiopathic systemic lupus erythematosus. Clin Pharmacol Ther 1982; 32:195-200.

22 Tan EM, Cohen AS, Fries JF, Masi AT, McShane DJ, Rothfield NF, et al. The 1982 revised criteria for the classification of systemic lupus erythematosus. Arthritis Rheum 1982;25:1271-7.

23 Sanz E J, Villen T, Alm C, Bertilsson L. S-mephenytoin hydroxylation phenotypes in a Swedish population determined after coadministration with debrisoquine. Clin Pharmacol Ther 1989;45:495-9.

24 Bathum L, Hansen TS, Horder M, Brosen K. A dual label oligonucleotide ligation assay for detection of the oligonucleotide ligation assay for detection of the
$C Y P 2 C 19^{\star} 1, C Y P 2 C 19^{\star} 2$ and $C Y P 2 C 19^{\star} 3$ allele involving $C Y P 2 C 19 * 1, C Y P 2 C 19^{\star} 2$ and $C Y P 2 C 19{ }^{\star} 3$ allele involving
time resolved fluorometry. Ther Drug Monit 1998;20:1-6.

25 Basci NE, Brosen K, Bozkurt A, Isimer A, Sayal A, Kayaalp SO. S-mephenytoin, sparteine and debrisoquine oxidation: genetic polymorphism in a Turkish population. $\mathrm{Br} \mathrm{J}$ Clin Pharmacol 1994,38:463-5.

26 Basci NE, Bozkurt A, Kortunay S, Sayal A, Isimer A, Kayaalp SO. Proguanil metabolism in relation to S-mephenytoin oxidation in a Turkish population. Br J Clin Pharmacol 1996;42:771-3.

27 Kortunay S, Basci NE, Bozkurt A, Kayaalp SO, Sayal A, Isimer A. The hydroxylation of omeprazole correlates with $\mathrm{S}$-mephenytoin and proguanil metabolism. Eur J Clin Pharmacol 1997;53:261-4.

28 Drohse A, Bathum L, Brosen K, Gram LF. Mephenytoin and sparteine oxidation: genetic polymorphisms in Denmark. Br J Clin Pharmacol 1989;27:620-5.

29 Flockhart DA, Clauw DJ, Sale EB, Hewett J, Woosley RL. Pharmacogenetic characteristic of the eosinophilia-myalgia syndrome. Clin Pharmacol Ther 1994;56:398-405. 